\title{
Convergence theorems of solutions of a generalized variational inequality
}

Li Yu ${ }^{1 *}$ and Ma Liang ${ }^{2}$

\author{
* Correspondence: \\ brucemath@139.com \\ 'School of Business Administration, \\ Henan University, Kaifeng 475000, \\ Henan Province, China \\ Full list of author information is \\ available at the end of the article
}

\section{Abstract}

The convex feasibility problem (CFP) of finding a point in the nonempty intersection $\bigcap_{m=1}^{r} C_{m}$ is considered, where $r \geq 1$ is an integer and each $C_{m}$ is assumed to be the solution set of a generalized variational inequality. Let $C$ be a nonempty closed and convex subset of a real Hilbert space $H$. Let $A_{m}, B_{m}: C \rightarrow H$ be relaxed cocoercive mappings for each $1 \leq m \leq r$. It is proved that the sequence $\left\{x_{n}\right\}$ generated in the following algorithm:

$$
x_{1} \in C, \quad x_{n+1}=\alpha_{n} u+\beta_{n} x_{n}+\gamma_{n} \sum_{m=1}^{r} \delta_{(m, n)} P_{C}\left(\tau_{m} B_{m} x_{n}-\lambda_{m} A_{m} x_{n}\right), \quad n \geq 1,
$$

where $u \in C$ is a fixed point, $\left\{\alpha_{n}\right\},\left\{\boldsymbol{\beta}_{n}\right\},\left\{\boldsymbol{\gamma}_{n}\right\},\left\{\boldsymbol{\delta}_{(1, n)}\right\}, \ldots$, and $\left\{\boldsymbol{\delta}_{(r, n)}\right\}$ are sequences in $(0,1)$ and $\left\{\tau_{m}\right\}_{m=1}^{r},\left\{\lambda_{m}\right\}_{m=1}^{r}$ are positive sequences, converges strongly to a solution of CFP provided that the control sequences satisfies certain restrictions.

2000 AMS Subject Classification: 47H05; 47H09; 47H10.

Keywords: nonexpansive mapping, fixed point, relaxed cocoercive mapping, variational inequality

\section{Introduction and Preliminaries}

Many problems in mathematics, in physical sciences and in real-world applications of various technological innovations can be modeled as a convex feasibility problem (CFP). This is the problem of finding a point in the intersection of finitely many closed convex sets in a real Hilbert spaces $H$. That is,

$$
\text { finding an } x \in \bigcap_{m=1}^{r} C_{m},
$$

where $r \geq 1$ is an integer and each $C_{m}$ is a nonempty closed and convex subset of $H$. There is a considerable investigation on CFP in the setting of Hilbert spaces which captures applications in various disciplines such as image restoration [1,2], computer tomography [3] and radiation therapy treatment planning [4].

Throughout this paper, we always assume that $H$ is a real Hilbert space, whose inner product and norm are denoted by $\langle\cdot, \cdot\rangle$ and $\|\cdot\|$. Let $C$ be a nonempty closed and convex subset of $H$ and $A: C \rightarrow H$ a nonlinear mapping. Recall the following definitions:

\section{SpringerOpen ${ }^{\circ}$}

(c) 2011 Yu and Liang; licensee Springer. This is an Open Access article distributed under the terms of the Creative Commons Attribution License (http://creativecommons.org/licenses/by/2.0), which permits unrestricted use, distribution, and reproduction in any medium, provided the original work is properly cited. 
(a) $A$ is said to be monotone if

$$
\langle A x-A y, x-y\rangle \geq 0, \quad \forall x, y \in C .
$$

(b) $A$ is said to be $\rho$-strongly monotone if there exists a positive real number $\rho>0$ such that

$$
\langle A x-A y, x-y\rangle \geq \rho\|x-y\|^{2}, \quad \forall x, y \in C .
$$

(c) $A$ is said to be $\eta$-cocoercive if there exists a positive real number $\eta>0$ such that

$$
\langle A x-A y, x-y\rangle \geq \eta\|A x-A y\|^{2}, \quad \forall x, y \in C .
$$

(d) $A$ is said to be relaxed $\eta$-cocoercive if there exists a positive real number $\eta>0$ such that

$$
\langle A x-A y, x-y\rangle \geq(-\eta)\|A x-A y\|^{2}, \quad \forall x, y \in C .
$$

(e) $A$ is said to be relaxed $(\eta, \rho)$-cocoercive if there exist positive real numbers $\eta, \rho$ $>0$ such that

$$
\langle A x-A y, x-y\rangle \geq(-\eta)\|A x-A y\|^{2}+\rho\|x-y\|^{2}, \quad \forall x, y \in C .
$$

The main purpose of this paper is to consider the following generalized variational inequality. Given nonlinear mappings $A: C \rightarrow H$ and $B: C \rightarrow H$, find a $u \in C$ such that

$$
\langle u-\tau B u+\lambda A u, v-u\rangle \geq 0, \quad \forall v \in C,
$$

where $\lambda$ and $\tau$ are two positive constants. In this paper, we use $G V I(C, B, A)$ to denote the set of solutions of the generalized variational inequality (1.2).

It is easy to see that an element $u \in C$ is a solution to the variational inequality (1.2) if and only if $u \in C$ is a fixed point of the mapping $P_{C}(\tau B-\lambda A)$, where $P_{C}$ denotes the metric projection from $H$ onto $C$. Indeed, we have the following relations:

$$
u=P_{C}(\tau B-\lambda A) u \Leftrightarrow\langle u-\tau B u+\lambda A u, v-u\rangle \geq 0, \quad \forall v \in C .
$$

Next, we consider a special case of (1.2). If $B=I$, the identity mapping and $\tau=1$, then the generalized variational inequality (1.1) is reduced to the following. Find $u \in C$ such that

$$
\langle A u, v-u\rangle \geq 0, \quad \forall v \in C .
$$

The variational inequality (1.4) emerging as a fascinating and interesting branch of mathematical and engineering sciences with a wide range of applications in industry, finance, economics, social, ecology, regional, pure and applied sciences was introduced by Stam-pacchia [5]. In this paper, we use $V I(C, A)$ to denote the set of solutions of the variational inequality (1.4).

Let $S: C \rightarrow C$ be a mapping. We use $F(S)$ to denote the set of fixed points of the mapping $S$. Recall that $S$ is said to be nonexpansive if

$$
\|S x-S y\| \leq\|x-y\|, \quad \forall x, y \in C .
$$


It is well known that if $C$ is nonempty bounded closed and convex subset of $H$, then the fixed point set of the nonexpansive mapping $S$ is nonempty, see [6] more details. Recently, fixed point problems of nonexpansive mappings have been considered by many authors; see, for example, [7-16].

Recall that $S$ is said to be demi-closed at the origin if for each sequence $\left\{x_{n}\right\}$ in $C, x_{n} \rightarrow$ $x_{0}$ and $S x_{n} \rightarrow 0$ imply $S x_{0}=0$, where $\rightarrow$ and $\rightarrow$ stand for weak convergence and strong convergence.

Recently, many authors considered the variational inequality (1.4) based on iterative methods; see [17-32]. For finding solutions to a variational inequality for a cocoercive mapping, Iiduka et al. [22] proved the following theorem.

Theorem ITT. Let $C$ be a nonempty closed convex subset of a real Hilbert space $H$ and let $A$ be an $\alpha$-cocoercive operator of $H$ into $H$ with $V I(C, A) \neq \varnothing$. Let $\left\{x_{n}\right\}$ be a sequence defined as follows. $x_{1}=x \in C$ and

$$
x_{n+1}=P_{C}\left(\alpha_{n} x_{n}+\left(1-\alpha_{n}\right) P_{C}\left(x_{n}-\lambda_{n} A x_{n}\right)\right)
$$

for every $n=1,2, \ldots$, where $C$ is the metric projection from $H$ onto $C,\left\{\alpha_{n}\right\}$ is a sequence in $[-1,1]$, and $\left\{\lambda_{n}\right\}$ is a sequence in $[0,2 \alpha]$. If $\left\{\alpha_{n}\right\}$ and $\left\{\lambda_{n}\right\}$ are chosen so that $\left\{\alpha_{n}\right\} \in[a, b]$ for some $a, b$ with $-1<a<b<1$ and $\left\{\lambda_{n}\right\} \in[c, d]$ for some $c, d$ with $0<$ $c<d<2(1+a) \alpha$, then $\left\{x_{n}\right\}$ converges weakly to some element of $V I(C, A)$.

Subsequently, Iiduka and Takahashi [23] further studied the problem of finding solutions of the classical variational inequality (1.4) for cocoercive mappings (inversestrongly monotone mappings) and nonexpansive mappings. They obtained a strong convergence theorem. More precisely, they proved the following theorem.

Theorem IT. Let $C$ be a closed convex subset of a real Hilbert space H. Let $S: C \rightarrow$ $C$ be a nonexpanisve mapping and $A$ an $\alpha$-cocoercive mapping of $C$ into $H$ such that $F$ $(S) \cap V I(C, A) \neq \varnothing$. Suppose $x_{1}=u \in C$ and $\left\{x_{n}\right\}$ is given by

$$
x_{n+1}=\alpha_{n} u+\left(1-\alpha_{n}\right) S P_{C}\left(x_{n}-\lambda_{n} A x_{n}\right)
$$

for every $n=1,2, \ldots$, where $\left\{\alpha_{n}\right\}$ is a sequence in $[0,1)$ and $\left\{\lambda_{n}\right\}$ is a sequence in $[a$, $b]$.

If $\left\{\alpha_{n}\right\}$ and $\left\{\lambda_{n}\right\}$ are chosen so that $\left\{\lambda_{n}\right\} \in[a, b]$ for some $a, b$ with $0<a<b<2 \alpha$,

$$
\lim _{n \rightarrow \infty} \alpha_{n}=0, \quad \sum_{n=1}^{\infty} \alpha_{n}=\infty, \quad \sum_{n=1}^{\infty}\left|\alpha_{n+1}-\alpha_{n}\right|<\infty \quad \text { and } \quad \sum_{n=1}^{\infty}\left|\lambda_{n+1}-\lambda_{n}\right|<\infty,
$$

then $\left\{x_{n}\right\}$ converges strongly to $P_{F(S) \cap V} I(C, A) x$.

In this paper, motivated by research work going on in this direction, we study the CFP in the case that each $C_{m}$ is a solution set of generalized variational inequality (1.2). Strong convergence theorems of solutions are established in the framework of real Hilbert spaces.

In order to prove our main results, we need the following lemmas.

Lemma 1.1 [33]. Let $\left\{x_{n}\right\}$ and $\left\{y_{n}\right\}$ be bounded sequences in a Hilbert space $H$ and $\left\{\beta_{n}\right\}$ a sequence in $(0,1)$ with

$$
0<\liminf _{n \rightarrow \infty} \beta_{n} \leq \limsup _{n \rightarrow \infty} \beta_{n}<1 .
$$


Suppose that $x_{n+1}=\left(1-\beta_{n}\right) y_{n}+\beta_{n} x_{n}$ for all integers $n \geq 0$ and

$$
\limsup _{n \rightarrow \infty}\left(\left\|y_{n+1}-y_{n}\right\|-\left\|x_{n+1}-x_{n}\right\|\right) \leq 0 .
$$

Then $\lim _{n \rightarrow \infty}|| y_{n}-x_{n} \|=0$.

Lemma 1.2 [34]. Let $C$ be a nonempty closed and convex subset of a real Hilbert space $H$. Let $S_{1}: C \rightarrow C$ and $S_{2}: C \rightarrow C$ be nonexpansive mappings on $C$. Suppose that $F\left(S_{1}\right) \cap F\left(S_{2}\right)$ is nonempty. Define a mapping $S: C \rightarrow C$ by

$$
S x=a S_{1} x+(1-a) S_{2} x, \quad \forall x \in C,
$$

where $a$ is a constant in $(0,1)$. Then $S$ is nonexpansive with $F(S)=F\left(S_{1}\right) \cap F\left(S_{2}\right)$.

Lemma 1.3 [35]. Let $C$ be a nonempty closed and convex subset of a real Hilbert space $H$ and $S: C \rightarrow C$ a nonexpansive mapping. Then $I-S$ is demi-closed at zero.

Lemma 1.4 [36]. Assume that $\left\{\alpha_{n}\right\}$ is a sequence of nonnegative real numbers such that

$$
\alpha_{n+1} \leq\left(1-\gamma_{n}\right) \alpha_{n}+\delta_{n}
$$

where $\left\{\gamma_{n}\right\}$ is a sequence in $(0,1)$ and $\left\{\delta_{n}\right\}$ is a sequence such that

(a) $\sum_{n=1}^{\infty} \gamma_{n}=\infty$;

(b) $\lim \sup _{n \rightarrow \infty} \delta_{n} / \gamma_{n} \leq 0$ or $\sum_{n=1}^{\infty}\left|\delta_{n}\right|<\infty$.

Then $\lim _{n \rightarrow \infty} \alpha_{n}=0$.

\section{Main results}

Theorem 2.1. Let $C$ be a nonempty closed and convex subset of a real Hilbert space $H$. Let $A_{m}: C \rightarrow H$ be a relaxed $\left(\eta_{m}, \rho_{m}\right)$-cocoercive and $\mu_{m}$-Lipschitz continuous mapping and $B_{m}: C \rightarrow H$ a relaxed $\left(\widehat{\eta}_{m}, \widehat{\rho}_{m}\right)$-cocoercive and $\widehat{\mu}_{m}$-Lipschitz continuous mapping for each $1 \leq m \leq r$. Assume that $\bigcap_{m=1}^{r} \operatorname{GVI}\left(C, B_{m}, A_{m}\right) \neq \emptyset$. Let $\left\{x_{n}\right\}$ be a sequence generated in the following manner:

$$
x_{1} \in C, \quad x_{n+1}=\alpha_{n} u+\beta_{n} x_{n}+\gamma_{n} \sum_{m=1}^{r} \delta_{(m, n)} P_{C}\left(\tau_{m} B_{m} x_{n}-\lambda_{m} A_{m} x_{n}\right), \quad n \geq 1,
$$

where $u \in C$ is a fixed point, $\left\{\alpha_{n}\right\},\left\{\beta_{n}\right\},\left\{\gamma_{n}\right\},\left\{\delta_{(1, n)}\right\}, \ldots$, and $\left\{\delta_{(r, n)}\right\}$ are sequences in $(0$, 1) satisfying the following restrictions:

(a) $\alpha_{n}+\beta_{n}+\gamma_{n}=\sum_{m=1}^{r} \delta_{(m, n)}=1, \forall n \geq 1$;

(b) $0<\lim \inf _{n \rightarrow \infty} \beta_{n} \leq \lim \sup _{n \rightarrow \infty} \beta_{n}<1$;

(c) $\lim _{n \rightarrow \infty} \alpha_{n}=0$ and $\sum_{n=1}^{\infty} \alpha_{n}=\infty$;

(d) $\lim _{n \rightarrow \infty} \delta_{(m, n)}=\delta_{m} \in(0,1), \forall 1 \leq m \leq r$,

And $\left\{\tau_{m}\right\}_{m=1}^{r},\left\{\lambda_{m}\right\}_{m=1}^{r}$ are two positive sequences such that

(e) $\sqrt{1-2 \lambda_{m} \rho_{m}+\lambda_{m}^{2} \mu_{m}^{2}+2 \lambda_{m} \eta_{m} \mu_{m}^{2}}+\sqrt{1-2 \widehat{\lambda}_{m} \widehat{\rho}_{m}+\widehat{\lambda}_{m}^{2} \widehat{\mu}_{m}^{2}+2 \widehat{\lambda}_{m} \widehat{\eta}_{m} \widehat{\mu}_{m}^{2}} \leq 1, \quad \forall 1 \leq m \leq r$.

Then the sequence $\left\{x_{n}\right\}$ generated in the iterative process $(\Upsilon)$ converges strongly to a 
common element $\bar{x} \in \bigcap_{m=1}^{r} \operatorname{GVI}\left(C, B_{m}, A_{m}\right)$, which uniquely solves the following variational inequality.

$$
\left\langle u-\bar{x}, \bar{x}-x^{*}\right\rangle \geq 0, \quad \forall x^{*} \in \bigcap_{m=1}^{r} \operatorname{GVI}\left(C, B_{m}, A_{m}\right) .
$$

Proof. First, we prove that the mapping $P_{C}\left(\tau_{m} B_{m}-\lambda_{m} A_{m}\right)$ is nonexpansive for each 1 $\leq m \leq r$. For each $x, y \in C$, we have

$$
\begin{aligned}
& \left\|P_{C}\left(\tau_{m} B_{m}-\lambda_{m} A_{m}\right) x-P_{C}\left(\tau_{m} B_{m}-\lambda_{m} A_{m}\right) y\right\| \\
& \leq\left\|\left(\tau_{m} B_{m}-\lambda_{m} A_{m}\right) x-\left(\tau_{m} B_{m}-\lambda_{m} A_{m}\right) y\right\| \\
& \leq\left\|(x-y)-\lambda_{m}\left(A_{m} x-A_{m} y\right)\right\|+\left\|(x-\gamma)-\tau_{m}\left(B_{m} x-B_{m} y\right)\right\| .
\end{aligned}
$$

It follows from the assumption that each $A_{m}$ is relaxed $\left(\eta_{m}, \rho_{m}\right)$-cocoercive and $\mu_{m^{-}}$ Lipschitz continuous that

$$
\begin{aligned}
& \left\|x-y-\lambda_{m}\left(A_{m} x-A_{m} \gamma\right)\right\|^{2} \\
& =\|x-\gamma\|^{2}-2 \lambda_{m}\left\langle A_{m} x-A_{m} \gamma, x-\gamma\right\rangle+\lambda_{m}^{2}\left\|A_{m} x-A_{m} y\right\|^{2} \\
& \leq\|x-\gamma\|^{2}-2 \lambda_{m}\left[\left(-\eta_{m}\right)\left\|A_{m} x-A_{m} \gamma\right\|^{2}+\rho_{m}\|x-y\|^{2}\right]+\lambda_{m}^{2} \mu_{m}^{2}\|x-y\|^{2} \\
& =\left(1-2 \lambda_{m} \rho_{m}+\lambda_{m}^{2} \mu_{m}^{2}\right)\|x-\gamma\|^{2}+2 \lambda_{m} \eta_{m}\left\|A_{m} x-A_{m} \gamma\right\|^{2} \\
& =\left(1-2 \lambda_{m} \rho_{m}+\lambda_{m}^{2} \mu_{m}^{2}\right)\|x-y\|^{2}+2 \lambda_{m} \eta_{m} \mu_{m}^{2}\left\|A_{m} x-A_{m} \gamma\right\|^{2} \\
& =\xi_{m}^{2}\|x-\gamma\|^{2},
\end{aligned}
$$

where $\xi_{m}=\sqrt{1-2 \lambda_{m} \rho_{m}+\lambda_{m}^{2} \mu_{m}^{2}+2 \lambda_{m} \eta_{m} \mu_{m}^{2}}$. This shows that

$$
\left\|x-y-\lambda_{m}\left(A_{m} x-A_{m} \gamma\right)\right\| \leq \xi_{m}\|x-y\| .
$$

In a similar way, we can obtain that

$$
\left\|x-y-\tau_{m}\left(B_{m} x-B_{m} y\right)\right\| \leq \zeta_{m}|| x-y \|,
$$

where $\zeta_{m}=\sqrt{1-2 \widehat{\lambda}_{m} \widehat{\rho}_{m}+\widehat{\lambda}_{m}^{2} \widehat{\mu}_{m}^{2}+2 \widehat{\lambda}_{m} \widehat{\eta}_{m} \widehat{\mu}_{m}^{2}}$. Substituting (2.2) and (2.3) into (2.1), we from the condition (e) see that $P_{C}\left(\tau_{m} B_{m}-\lambda_{m} A_{m}\right)$ is nonexpansive for each $1 \leq m \leq$ r. Put

$$
y_{n}=\sum_{m=1}^{r} \delta_{(m, n)} P_{C}\left(\tau_{m} B_{m} x_{n}-\lambda_{m} A_{m} x_{n}\right), \quad \forall n \geq 1
$$

Fixing $p \in \bigcap_{m=1}^{r} \operatorname{GVI}\left(C, B_{m}, A_{m}\right)$, we see that

$$
\left\|y_{n}-p\right\| \leq\left\|x_{n}-p\right\| .
$$

It follows that

$$
\begin{aligned}
\left\|x_{n+1}-p\right\| & =\left\|\alpha_{n} u+\beta_{n} x_{n}+\gamma_{n} y_{n}-p\right\| \\
& \leq \alpha_{n}\|u-p\|+\beta_{n}\left\|x_{n}-p\right\|+\gamma_{n}\left\|y_{n}-p\right\| \\
& \leq \alpha_{n}\|u-p\|+\beta_{n}\left\|x_{n}-p\right\|+\gamma_{n}\left\|x_{n}-p\right\| \\
& =\alpha_{n}\|u-p\|+\left(1-\alpha_{n}\right)\left\|x_{n}-p\right\| .
\end{aligned}
$$

By mathematical inductions we arrive at

$$
\left\|x_{n}-p\right\| \leq \max \left\{\|u-p\|,\left\|x_{1}-p\right\|\right\}, \quad \forall n \geq 1 .
$$


Since the mapping $P_{C}\left(\tau_{m} B_{m}-\lambda_{m} A_{m}\right)$ is nonexpansive for each $1 \leq m \leq r$, we see that

$$
\begin{aligned}
& \left\|y_{n+1}-y_{n}\right\| \\
& =\left\|\sum_{m=1}^{r} \delta_{(m,(n+1))} P_{C}\left(\tau_{m} B_{m} x_{n+1}-\lambda_{m} A_{m} x_{n+1}\right)-\sum_{m=1}^{r} \delta_{(m, n)} P_{C}\left(\tau_{m} B_{m} x_{n}-\lambda_{m} A_{m} x_{n}\right)\right\| \\
& \leq\left\|x_{n+1}-x_{n}\right\|+M \sum_{m=1}^{r}\left|\delta_{(m,(n+1))}-\delta_{(m, n)}\right|,
\end{aligned}
$$

where $M$ is an appropriate constant such that

$$
M=\max \left\{\sup _{n \geq 1}\left\|P_{C}\left(\tau_{m} B_{m} x_{n}-\lambda_{m} A_{m} x_{n}\right)\right\|, \forall 1 \leq m \leq r\right\} .
$$

Put $l_{n}=\frac{x_{n+1}-\beta_{n} x_{n}}{1-\beta_{n}}$, for all $n \geq 1$. That is,

$$
x_{n+1}=\left(1-\beta_{n}\right) l_{n}+\beta_{n} x_{n,} \quad \forall n \geq 1 .
$$

Now, we estimate $\left\|l_{n+1}-l_{n}\right\|$. Note that

$$
\begin{aligned}
l_{n+1}-l_{n} & =\frac{\alpha_{n+1} u+\gamma_{n+1} \gamma_{n+1}}{1-\beta_{n+1}}-\frac{\alpha_{n} u+\gamma_{n} \gamma_{n}}{1-\beta_{n}} \\
& =\frac{\alpha_{n+1}}{1-\beta_{n+1}}\left(u-\gamma_{n+1}\right)+\frac{\alpha_{n}}{1-\beta_{n}}\left(y_{n}-u\right)+\gamma_{n+1}-y_{n}
\end{aligned}
$$

which combines with (2.4) yields that

$$
\begin{aligned}
& \left\|l_{n+1}-l_{n}\right\|-\left\|x_{n+1}-x_{n}\right\| \\
& \leq \frac{\alpha_{n+1}}{1-\beta_{n+1}}\left\|u-y_{n+1}\right\|+\frac{\alpha_{n}}{1-\beta_{n}}\left\|\gamma_{n}-u\right\|+M \sum_{m=1}^{r}\left|\delta_{(m,(n+1))}-\delta_{(m, n)}\right| .
\end{aligned}
$$

It follows from the conditions (b), (c) and (d) that

$$
\limsup _{n \rightarrow \infty}\left(\left\|l_{n+1}-l_{n}\right\|-\left\|x_{n+1}-x_{n+1}\right\|\right) \leq 0 .
$$

It follows from Lemma 1.1 that $\lim _{n \rightarrow \infty}|| l_{n}-x_{n} \|=0$. In view of (2.5), we see that $x_{n}$ $+1 x_{n}=\left(1-\beta_{n}\right)\left(l_{n}-x_{n}\right)$. It follows that

$$
\lim _{n \rightarrow \infty}|| x_{n+1}-x_{n} \|=0 \text {. }
$$

On the other hand, from the iterative algorithm $(\Upsilon)$, we see that $x_{n}+1-x_{n}=\alpha_{n}(u$ $\left.x_{n}\right)+\gamma_{n}\left(y_{n}-x_{n}\right)$. It follows from (2.6) and the conditions (b), (c) that

$$
\lim _{n \rightarrow \infty}\left\|y_{n}-x_{n}\right\|=0 \text {. }
$$

Next, we show that $\lim \sup _{n \rightarrow \infty}\left\langle u-\bar{x}, x_{n}-\bar{x}\right\rangle \leq 0$. To show it, we can choose a subsequence $\left\{x_{n_{i}}\right\}$ of $\left\{x_{n}\right\}$ such that

$$
\limsup _{n \rightarrow \infty}\left\langle u-\bar{x}, x_{n}-\bar{x}\right\rangle=\lim _{i \rightarrow \infty}\left\langle u-\bar{x}, x_{n_{i}}-\bar{x}\right\rangle .
$$

Since $\left\{x_{n_{i}}\right\}$ is bounded, we obtain that there exists a subsequence $\left\{x_{n_{i_{j}}}\right\}$ of $\left\{x_{n_{i}}\right\}$ which converges weakly to $q$. Without loss of generality, we may assume that $x_{n_{i}} \rightarrow q$. Next, we show that $q \in \bigcap_{m=1}^{r} \operatorname{GVI}\left(C, B_{m}, A_{m}\right)$. Define a mapping $R: C \rightarrow C$ by 


$$
R x=\sum_{m=1}^{r} \delta_{m} P_{C}\left(\tau_{m} B_{m}-\lambda_{m} A_{m}\right) x, \quad \forall x \in C,
$$

where $\delta_{m}=\lim _{n \rightarrow \infty} \delta_{(m, n)}$. From Lemma 1.2, we see that $R$ is nonexpansive with

$$
F(R)=\bigcap_{m=1}^{r} F\left(P_{C}\left(\tau_{m} B_{m}-\lambda_{m} A_{m}\right)\right)=\bigcap_{m=1}^{r} G V I\left(C, B_{m}, A_{m}\right) .
$$

Now, we show that $R x_{n}-x_{n} \rightarrow 0$ as $n \rightarrow \infty$. Note that

$$
\begin{aligned}
& \left\|R x_{n}-x_{n}\right\| \\
& =\left\|\sum_{m=1}^{r} \delta_{m} P_{C}\left(\tau_{m} B_{m}-\lambda_{m} A_{m}\right) x_{n}-\sum_{m=1}^{r} \delta_{(m, n)} P_{C}\left(\tau_{m} B_{m} x_{n}-\lambda_{m} A_{m} x_{n}\right)\right\|+\left\|y_{n}-x_{n}\right\| \\
& \leq M \sum_{m=1}^{r}\left|\delta_{(m, n)}-\delta_{m}\right|+\left\|y_{n}-x_{n}\right\| .
\end{aligned}
$$

From the condition (d) and (2.7), we obtain that $\lim _{n \rightarrow \infty} \| R x_{n}-x_{n}||=0$. From Lemma 1.3 , we see that

$$
q \in F(R)=\bigcap_{m=1}^{r} F\left(P_{C}\left(\tau_{m} B_{m}-\lambda_{m} A_{m}\right)\right)=\bigcap_{m=1}^{r} \operatorname{GVI}\left(C, B_{m}, A_{m}\right) .
$$

In view of (2.8), we arrive at

$$
\limsup _{n \rightarrow \infty}\left\langle u-\bar{x}, x_{n}-\bar{x}\right\rangle=\langle u-\bar{x}, q-\bar{x}\rangle \leq 0 .
$$

Finally, we show that $x_{n} \rightarrow \bar{x}$ as $n-\infty$. Note that

$$
\begin{aligned}
& \left\|x_{n+1}-\bar{x}\right\|^{2} \\
& =\left\langle\alpha_{n} u+\beta_{n} x_{n}+\gamma_{n} y_{n}-\bar{x}, x_{n+1}-\bar{x}\right\rangle \\
& =\alpha_{n}\left\langle u-\bar{x}, x_{n+1}-\bar{x}\right\rangle+\beta_{n}\left\langle x_{n}-\bar{x}, x_{n+1}-\bar{x}\right\rangle+\gamma_{n}\left\langle y_{n}-\bar{x}, x_{n+1}-\bar{x}\right\rangle \\
& \leq \alpha_{n}\left\langle u-\bar{x}, x_{n+1}-\bar{x}\right\rangle+\beta_{n}\left\|x_{n}-\bar{x}\right\|\left\|x_{n+1}-\bar{x}\right\|+\gamma_{n}\left\|y_{n}-\bar{x}\right\|\left\|x_{n+1}-\bar{x}\right\| \\
& \leq \alpha_{n}\left\langle u-\bar{x}, x_{n+1}-\bar{x}\right\rangle+\left(1-\alpha_{n}\right)\left\|x_{n}-\bar{x}\right\|\left\|x_{n+1}-\bar{x}\right\| \\
& \leq \frac{1-\alpha_{n}}{2}\left(\left\|x_{n}-\bar{x}\right\|^{2}+\left\|x_{n+1}-\bar{x}\right\|^{2}\right)+\alpha_{n}\left\langle u-\bar{x}, x_{n+1}-\bar{x}\right\rangle,
\end{aligned}
$$

which implies that

$$
\left\|x_{n+1}-\bar{x}\right\|^{2} \leq\left(1-\alpha_{n}\right)\left\|x_{n}-\bar{x}\right\|^{2}+2 \alpha_{n}\left\langle u-\bar{x}, x_{n+1}-\bar{x}\right\rangle .
$$

From the condition (c), (2.9) and applying Lemma 1.4 to (2.10), we obtain that

$$
\lim _{n \rightarrow \infty}\left\|x_{n}-\bar{x}\right\|=0 \text {. }
$$

This completes the proof.

If $B_{m} \equiv I$, the identity mapping and $\tau_{m} \equiv 1$, then Theorem 2.1 is reduced to the following result on the classical variational inequality (1.4).

Corollary 2.2. Let $C$ be a nonempty closed and convex subset of a real Hilbert space $H$. Let $A_{m}: C \rightarrow H$ be a relaxed $\left(\eta_{m}, \rho_{m}\right)$-cocoercive and $\mu_{m}$-Lipschitz continuous mapping for each $1 \leq m \leq r$. Assume that $\bigcap_{m=1}^{r} \operatorname{VI}\left(C, A_{m}\right) \neq \emptyset$. Let $\left\{x_{n}\right\}$ be a sequence generated by the following manner: 


$$
x_{1} \in C, \quad x_{n+1}=\alpha_{n} u+\beta_{n} x_{n}+\gamma_{n} \sum_{m=1}^{r} \delta_{(m, n)} P_{C}\left(x_{n}-\lambda_{m} A_{m} x_{n}\right), \quad n \geq 1,
$$

where $u \in C$ is a fixed point, $\left\{\alpha_{n}\right\},\left\{\beta_{n}\right\},\left\{\gamma_{n}\right\},\left\{\delta_{(1, n)}\right\}, \ldots$, and $\left\{\delta_{(r, n)}\right\}$ are sequences in $(0$, 1) satisfying the following restrictions.

(a) $\alpha_{n}+\beta_{n}+\gamma_{n}=\sum_{m=1}^{r} \delta_{(m, n)}=1, \forall n \geq 1$;

(b) $0<\lim \inf _{n \rightarrow \infty} \beta_{n} \leq \lim \sup _{n \rightarrow \infty} \beta_{n}<1$;

(c) $\lim _{n \rightarrow \infty} \alpha_{n}=0$ and $\sum_{n=1}^{\infty} \alpha=\infty$;

(d) $\lim _{n \rightarrow \infty} \delta_{(m, n)}=\delta_{m} \in(0,1), \forall 1 \leq m \leq r$, and $\left\{\lambda_{m}\right\}_{m=1}^{r}$ is a positive sequence such that

(e) $\lambda_{m} \leq \frac{2 \rho_{m}-2 \eta_{m} \mu_{m}^{2}}{\mu_{m}^{2}}, \forall 1 \leq m \leq r$.

Then the sequence $\left\{x_{n}\right\}$ converges strongly to a common element $\bar{x} \in \bigcap_{m=1}^{r} \operatorname{VI}\left(C, A_{m}\right)$, which uniquely solves the following variational inequality

$$
\left\langle u-\bar{x}, \bar{x}-x^{*}\right\rangle \geq 0, \quad \forall x^{*} \in \bigcap_{m=1}^{r} \operatorname{VI}\left(C, A_{m}\right) .
$$

If $r=1$, then Theorem 2.1 is reduced to the following.

Corollary 2.3. Let $C$ be a nonempty closed and convex subset of a real Hilbert space $H$. Let $A: C \rightarrow H$ be a relaxed $(\eta, \rho)$-cocoercive and $\mu$-Lipschitz continuous mapping and $B: C \rightarrow H$ a relaxed $(\widehat{\eta}, \widehat{\rho})$-cocoercive and $\widehat{\mu}$-Lipschitz continuous mapping. Assume that $G V I(C, B, A)$ is not empty. Let $\left\{x_{n}\right\}$ be a sequence generated in the following manner:

$$
x_{1} \in C, \quad x_{n+1}=\alpha_{n} u+\beta_{n} x_{n}+\gamma_{n} P_{C}\left(\tau B x_{n}-\lambda A x_{n}\right), \quad n \geq 1,
$$

where $u \in C$ is a fixed point, $\left\{\alpha_{n}\right\},\left\{\beta_{n}\right\}$ and $\left\{\gamma_{n}\right\}$ are sequences in $(0,1)$ satisfying the following restrictions.

(a) $\alpha_{n}+\beta_{n}+\gamma_{n}=1, \forall_{n} \geq 1$;

(b) $0<\lim \inf _{n \rightarrow \infty} \beta_{n} \leq \lim \sup _{n \rightarrow \infty} \beta_{n}<1$;

(c) $\lim _{n \rightarrow \infty} \alpha_{n}=0$ and $\sum_{n=1}^{\infty} \alpha_{n}=\infty$

(d) $\sqrt{1-2 \lambda \rho+\lambda^{2} \mu^{2}+2 \lambda \eta \mu^{2}}+\sqrt{1-2 \widehat{\lambda} \widehat{\rho}+\widehat{\lambda}^{2} \widehat{\mu}^{2}+2 \widehat{\lambda} \widehat{\eta} \widehat{\mu}^{2}} \leq 1$.

Then the sequence $\left\{x_{n}\right\}$ converges strongly to a common element $\bar{x} \in G V I(C, B, A)$, which uniquely solves the following variational inequality

$$
\left\langle u-\bar{x}, \bar{x}-x^{*}\right\rangle \geq 0, \quad \forall x^{*} \in \operatorname{GVI}(C, B, A) .
$$

For the variational inequality (1.4), we can obtain from Corollary 2.3 the following immediately.

Corollary 2.4. Let $C$ be a nonempty closed and convex subset of a real Hilbert space $H$. Let $A: C \rightarrow H$ be a relaxed $(\eta, \rho)$-cocoercive and $\mu$-Lipschitz continuous mapping. Assume that $V I(C, A)$ is not empty. Let $\left\{x_{n}\right\}$ be a sequence generated in the following manner:

$$
x_{1} \in C, \quad x_{n+1}=\alpha_{n} u+\beta_{n} x_{n}+\gamma_{n} P_{C}\left(x_{n}-\lambda A x_{n}\right), \quad n \geq 1,
$$


where $u \in C$ is a fixed point, $\left\{\alpha_{n}\right\},\left\{\beta_{n}\right\}$ and $\left\{\gamma_{n}\right\}$ are sequences in $(0,1)$ satisfying the following restrictions.

(a) $\alpha_{n}+\beta_{n}+\gamma_{n}=1, \forall n \geq 1$

(b) $0<\lim \inf _{n \rightarrow \infty} \beta_{n} \leq \lim \sup _{n \rightarrow \infty} \beta_{n}<1$;

(c) $\lim _{n \rightarrow \infty} \alpha_{n}=0$ and $\sum_{n=1}^{\infty} \alpha_{n}=\infty$;

(d) $\lambda \leq \frac{2 \rho-2 \eta \mu^{2}}{\mu^{2}}$.

Then the sequence $\left\{x_{n}\right\}$ converges strongly to a common element $\bar{x} \in \operatorname{VI}(C, A)$, which uniquely solves the following variational inequality

$$
\left\langle u-\bar{x}, \bar{x}-x^{*}\right\rangle \geq 0, \quad \forall x^{*} \in \operatorname{VI}(C, A) .
$$

Remark 2.5. In this paper, the generalized variational inequality (1.2), which includes the classical variational inequality (1.4) as a special case, is considered based on iterative methods. Strong convergence theorems are established under mild restrictions imposed on the parameters. It is of interest to extend the main results presented in this paper to the framework of Banach spaces.

\section{Abbreviation}

CFP: convex feasibility problem.

\section{Acknowledgements}

This work was supported by the National Natural Science Foundation of China under Grant no. 70871081 and Important Science and Technology Research Project of Henan province, China (102102210022).

\section{Author details}

${ }^{1}$ School of Business Administration, Henan University, Kaifeng 475000, Henan Province, China ${ }^{2}$ School of Management, University of Shanghai for Science and Technology, Shanghai 200093, China

\section{Authors' contributions}

LY designed and performed all the steps of proof in this research and also wrote the paper. ML participated in the design of the study. All authors read and approved the final manuscript.

\section{Competing interests}

The authors declare that they have no competing interests.

Received: 14 November 2010 Accepted: 25 July 2011 Published: 25 July 2011

\section{References}

1. Combettes PL: The convex feasibility problem: in image recovery. In Advances in Imaging and Electron Physics. Volume 95. Edited by: Hawkes P. Academic Press, Orlando; 1996:155-270

2. Kotzer T, Cohen N, Shamir J: Images to ration by a novel method of parallel projection onto constraint sets. Opt Lett 1995, 20:1172-1174

3. Sezan Ml, Stark H: Application of convex projection theory to image recovery in tomograph and related areas. In Image Recovery: Theory and Application. Edited by: Stark H. Academic Press, Orlando; 1987:155-270.

4. Censor Y, Zenios SA: Parallel Optimization. Theory, Algorithms, and Applications, Numerical Mathematics and Scientific Computation. Oxford University Press, New York; 1997.

5. Stampacchia G: Formes bilineaires coercitives sur les ensembles convexes. CR Acad Sci Paris 1964, 258:4413-4416.

6. Baillon JB: Quelques aspects de la theorie des points fixes dans les espaces de Banach. I, II, Séminaire d'Analyse Fonctionnelle (1978-1979). Exp. No. 7-8, Ecole Polytech., (in French). Palaiseau 1979, 45

7. Qin X, Su Y: Approximation of a zero point of accretive operator in Banach spaces. J Math Anal Appl 2007, 329:415-424.

8. Qin X, Su Y: Strong convergence theorems for relatively nonexpansive mappings in a Banach space. Nonlinear Anal 2007, 67:1958-1965.

9. Cho YJ, Kang SM, Qin X: Approximation of common fixed points of an infinite family of nonex-pansive mappings in Banach spaces. Comput Math Appl 2008, 56:2058-2064

10. Park S: Fixed point theorems in locally G-convex spaces. Nonlinear Anal 2002, 48:869-879.

11. Park S: Fixed point theory of multimaps in abstract convex uniform spaces. Nonlinear Anal 2009, 71:2468-2480. 
12. Qin X, Cho YJ, Kang Jl, Kang SM: Strong convergence theorems for an infinite family of nonex-pansive mappings in Banach spaces. J Comput Appl Math 2009, 230:121-127.

13. Kim JK, Nam YM, Sim JY: Convergence theorems of implicit iterative sequences for a finite family of asymptotically quasi-nonexpansive type mappings. Nonlinear Anal 2009, 71:e2839-e2848.

14. Qin X, Cho YJ, Kang SM, Zho H: Convergence of a modified Halpern-type iteration algorithm for quasi-खnonexpansive mappings. Appl Math Lett 2009, 22:1051-1055.

15. Qin X, Cho SY, Zhou H: Common fixed points of a pair of non-expansive mappings with applications to convex feasibility problems. Glasgow Math J 2010, 52:241-252.

16. Wu C, Cho SY, Shang M: Moudafi's viscosity approximations with demi-continuous and strong pseudo-contractions for non-expansive semigroups. J Inequal Appl 2010, 2010:Article ID 645498.

17. Cho SY: Approximation of solutions of a generalized variational inequality problem based on iterative methods. Commun Korean Math Soc 2010, 25:207-214.

18. Kim JK, Cho SY, Qin X: Hybrid projection algorithms for generalized equilibrium problems and strictly pseudocontractive mappings. J Inequal Appl 2010, 2010:Article ID 312602.

19. Hao Y: Strong convergence of an iterative method for inverse strongly accretive operators. J Inequal App/ 2008, 2008:Article ID 420989

20. Qin X, Cho YJ, Kang SM: Convergence theorems of common elements for equilibrium problems and fixed point problems in Banach spaces. J Comput Appl Math 2009, 225:20-30.

21. Qin X, Shang M, Su Y: Strong convergence of a general iterative algorithm for equilibrium problems and variational inequality problems. Math Comput Model 2008, 48:1033-1046.

22. liduka $\mathrm{H}$, Takahashi W, Toyoda M: Approximation of solutions of variational inequalities for monotone mappings. PanAmer Math J 2004, 14:49-61.

23. liduka $\mathrm{H}$, Takahashi W: Strong convergence theorems for nonexpansive mappings and inverse-strongly monotone mappings. Nonlinear Anal 2005, 61:341-350.

24. liduka $\mathrm{H}$, Takahashi W: Weak convergence of a projection algorithm for variational inequalities in a Banach space. $J$ Math Anal Appl 2008, 339:668-679.

25. Qin X, Cho SY, Kang SM: Some results on generalized equilibrium problems involving a family of nonexpansive mappings. Appl Math Comput 2010, 217:3113-3126

26. Park S, Kang BG: Generalized variational inequalities and fixed point theorems. Nonlinear Anal 1998, 31:207-216.

27. Park S, Kum S: An application of a Browder-type fixed point theorem to generalized variational inequalities. J Math Anal Appl 1998, 218:519-526.

28. Park S: Fixed points, intersection theorems, variational inequalities, and equilibrium theorems. Int J Math Math Sci 2000, 24(2):73-93.

29. Park S, Chen MP: Generalized variational inequalities of the Hartman-Stampacchia-Browder type. J Inequal Appl 1998, 2:71-87.

30. Qin X, Chang SS, Cho YJ: Iterative methods for generalized equilibrium problems and fixed point problems with applications. Nonlinear Anal 2010, 11:2963-2972.

31. Qin X, Cho YJ, Kang SM: Viscosity approximation methods for generalized equilibrium problems and fixed point problems with applications. Nonlinear Anal 2010, 72:99-112.

32. Takahashi W, Toyoda M: Weak convergence theorems for nonexpansive mappings and monotone mappings. J Optim Theory Appl 2003, 118:417-428.

33. Suzuki T: Strong convergence of Krasnoselskii and Mann's type sequences for one-parameter non-expansive semigroups without Bochne integrals. J Math Anal Appl 2005, 305:227-239.

34. Bruck RE: Properties of fixed point sets of nonexpansive mappings in Banach spaces. Trans Am Math Soc 1973, 179:251-262.

35. Browder FE: Nonlinear operators and nonlinear equations of evolution in Banach spaces. Proc Symp Pure Math 1976, 18:78-81.

36. Liu LS: Ishikawa and Mann iterative processes with errors for nonlinear strongly acretive mappings in Banach spaces. J Math Anal Appl 1995, 194:114-125.

doi:10.1186/1687-1812-2011-19

Cite this article as: Yu and Liang: Convergence theorems of solutions of a generalized variational inequality.

Fixed Point Theory and Applications 2011 2011:19.

\section{Submit your manuscript to a SpringerOpen ${ }^{\circ}$ journal and benefit from:}

- Convenient online submission

- Rigorous peer review

- Immediate publication on acceptance

- Open access: articles freely available online

- High visibility within the field

- Retaining the copyright to your article

Submit your next manuscript at $\gg$ springeropen.com 